\title{
A case study report on integrating statistics, problem-based learning, and computerized data analysis
}

\author{
THOMAS T. HEWETT and DOUGLAS V. PORPORA \\ Drexel University, Philadelphia, Pennsylvania
}

\begin{abstract}
This paper addresses the pedagogical advantages of teaching statistics not as a stand-alone subject in itself, but rather as a topic integrated into teaching hands-on, problem-based computer-assisted data analysis. For over 10 years, such a two-term course has been taught at Drexel University in lieu of the usual statistics courses formerly taken by undergraduate majors in psychology and sociology. One virtue of the courses as currently implemented is that students seem to learn not just how to perform statistical procedures but how to apply them on their own.
\end{abstract}

How should statistics be taught? On the basis of a comprehensive review of educational literature on the teaching of statistics, Garfield (1995) has suggested that the standard classroom approach, based on textbook and lectures, is not the most effective. On the basis of Garfield's review, the things that do seem to help statistics students are activity-based courses, the use of small group learning experiences, substantial frequent feedback, and the use of software that allows students to interact with real data. Garfield ends her review with a call for statistics teachers to somehow implement these principles.

The purpose of this paper is to offer one course model in which many of the recommendations developed in Garfield's (1995) review have been implemented. Although the pedagogical model and assumptions that guide these courses were originally developed without knowledge of the research findings reviewed by Garfield, they were developed in response to the same dissatisfactions with the textbook and lecture model that Garfield describes. The model in use at Drexel University's Department of Psychology, Sociology, and Anthropology was designed to solve a practical problem confronting our psychology and sociology programs. After having completed two terms of their standard statistics courses, many of our students were intimidated both by statistics and by computer-assisted data analysis. They generally wanted nothing more to do with either, and, as a consequence, they were avoiding statistical data analysis in their senior

Work on this paper was supported in part by NSF CISE Grant CCR9527130 and in part by NSF CISE Grant IIS- 9873005 to T.T.H. The authors thank Dana Sari for her thoughtful comments on this paper and David Lane and two anonymous reviewers for their comments on an earlier draft of this paper. In particular, David Lane's insights and suggestions helped the authors gain an important perspective on what we were trying to communicate. Correspondence should be addressed to T. T. Hewett, Department of Psychology/Sociology/Anthropology, Drexel University, Philadelphia, PA 19104 (e-mail: hewett@drexel.edu). thesis projects. Similarly, they were not seeking out opportunities to contribute to faculty research projects.

Currently, we offer a two-term sequence of classes in computer-assisted data analysis that, for over a decade now, has been required of students in our psychology and sociology programs. As will be seen from the discussion below, our experiences lend support to the recommendations that Garfield (1995) develops in her literature review. Furthermore, several results of studies reviewed by Garfield seem to provide a research-based empirical justification for many of the choices we made in designing the course model described here.

Since our original intent was to cope with an immediate, on-going practical problem and not to conduct basic research, our course model has not been formally evaluated. Yet, given that the courses to be described fit quite well with the pedagogical recommendations following from the research literature and given that some of the implementation of those recommendations is not otherwise straightforward, there seems to be value in sharing the model and methods with the larger community. From a purely pragmatic standpoint, the authors, the psychology and sociology students and faculty, and some faculty and students from outside the department judge the courses described here to be a success. This paper will also report some of the anecdotal bases for that judgment.

\section{SOME LITERATURE ON TEACHING STATISTICS}

The presentation in this paper is guided by two recent, comprehensive reviews of the literature on statistics instruction (Becker, 1996; Garfield, 1995). For example, Becker (1996) quantitatively categorizes the types of articles written on statistics instruction, $70 \%$ of which are not rigorously empirical. However, the more rigorous empirical studies reviewed by Becker suggest support for the importance of student interaction with real data, par- 
ticularly computer-assisted data analysis; other studies suggest support for the importance of frequent interaction between teacher and student and among students and for the importance of personalized attention (Becker 1996).

\section{What Should Students Be Learning?}

Garfield's (1995) review provides an evaluative assessment of the literature on the teaching of statistics. She notes that previous literature reviews (e.g., Garfield \& Ahlgren, 1988; Scholz, 1991; Shaughnessy's (1977) review as cited in Garfield, 1995) strongly suggest that students in statistics courses are not learning what we want them to learn. One important point stressed by Garfield (1995) is that we need to be clearer about what we want students to learn. Drawing on the thinking of Hogg and Moore (as cited in Garfield, 1995), Garfield suggests that we should neither expect nor really want students to retain detailed technical knowledge, such as how to compute a standard deviation. What we should expect and desire students to retain are the broad concepts of statistical thinking, such as the idea of variability, the difference between causation and covariation, and the relation between representativeness and sampling technique. Additionally, statistics instruction should strive for certain attitudinal changes, such as an appreciation for the importance of statistics.

\section{What Factors Help Students Learn?}

From her review of the literature, Garfield (1995) identifies a number of factors that seem to enhance student learning. Activity-based courses appear to be helpful (Jones's study as cited in Garfield, 1995; Shaughnessy, 1977), as do feedback to students on their misconceptions (Mevarech, 1983) and repetition of concepts. Garfield notes that there seem to be benefits from computer software that enables students to interact with data (Rubin, Rosebery, \& Bruce's study and Weissglass \& Cummings's study as cited in Garfield, 1995) and to visualize abstract concepts (Rubin et al.'s study as cited in Garfield, 1995). More generally, Garfield's review suggests that students learn better if they are engaged with the material, if they are working in small groups, and if they are constructing their own knowledge rather than listening passively (National Research Council report and Resnick's study as cited in Garfield, 1995; von Glasersfeld, 1987).

\section{DESIGN HISTORY OF THE INTEGRATED COURSE}

The primary focus of the pedagogical model described in this paper is computer-assisted data analysis, wherein students learn statistics through application to real data. The institutional context for the course model is that of a university that emphasizes both research and teaching. All courses are taught on a 10 -week quarter system. The department faculty is composed of psychologists, sociologists, and anthropologists and currently offers undergraduate majors in psychology and in sociology. The de- partment also offers a Ph.D. program in psychology with an emphasis in clinical neuropsychology. Most departmental faculty teach at both the graduate and the undergraduate level and are eager to include advanced undergraduates as research collaborators in relationships of collegial apprenticeship. Accordingly, one long-term departmental objective has been to provide research opportunities for undergraduates who are interested, willing, and able to engage in supervised quantitative research. Another long-term goal has been to simultaneously provide statistical and data analytic tools useful to students with more immediately pragmatic employment goals.

The problem was that by their senior year, psychology majors and sociology majors were almost all unable and unwilling to pursue quantitative research, either for their senior theses or in independent study with a faculty member. The two-term statistics sequence required of our students followed the conventional textbook and lecture model. However, these courses were effectively discouraging students from engaging in the use of computers, statistics, and data analysis. Even when students completed their statistics courses successfully, they remained unable to analyze actual data. They might vaguely remember how to do a $t$ test if presented with a preshaped problem in a text book; however, they had no idea how to approach a data set to shape an analysis of their own.

The initial foray into a problem-based data analysis course was an attempt to try to solve the problems inherent in the traditional instructional design with a new capstone course. This initial one-term course focused on computer-assisted data analysis for students who had completed their two terms of required statistics. However, given that most of our students lacked a sufficient grasp of statistical principles to benefit from the course, it was also necessary to integrate reviews of statistical material into discussions of the use of computer software.

Over time, this single class evolved, and we began to realize that, rather than creating a capstone experience, what we had developed was a course that should be taught at an introductory or fundamentals level. Ultimately, therefore, we expanded the class into a two-term sequence of courses intended to teach students computing, statistics, and data analysis all in a single integrated package. This sequence has now replaced the previously required textbook and lecture courses in statistics.

\section{CURRENT COURSE DESIGN AND IMPLEMENTATION}

The two-term sequence in computer-assisted data analysis takes students through the entire data analysis process from beginning to end. Students begin with questionnaires, which they learn to code and enter into the computer themselves. They learn to "clean" the data, searching for coding errors. They also learn to conduct univariate analyses and then move on to bivariate and multivariate analyses. During their second term, students learn how to create and test causal models. They finish 
the term with a written report on a causal model that they themselves have formulated.

At each stage of the process, students are introduced to what they need to know in terms of statistics or computer procedures to accomplish an immediate task - a task that is always a step in the process of data analysis. Thus, in contrast to one conventional approach to statistics, the sequence does not begin with early coverage of a section on probability. Very directed principles of probability are introduced only later when the students are learning chi-square analysis and hypothesis testing. Instead, at the beginning, students are taught about variables and, specifically, are taught to distinguish between variables, values, and cases-something many students find conceptually difficult. At this stage, students are introduced to levels of measurement. For example, one homework assignment is to determine the measurement level of each variable in the data set.

At the same time that students are learning such basic statistical principles, they are also being introduced to a research-grade computer software package, either SPSS or SAS. It is therefore also necessary to teach students the commands of an editing and programming language used for building and manipulating their files. While being introduced to the statistical software used in the classes, students are also taught to look for miscoded data by running frequencies and checking for values beyond the appropriate range. At the same time, they are introduced to measures of central tendency and dispersion.

After covering univariate analysis, the course begins to consider causal modeling. Considerable time is spent distinguishing causality from mere covariation, and covariation is itself presented in terms of the concepts of statistical independence and dependence. If, as Garfield's (1995) review suggests, the ability to distinguish causality from covariation should be one essential outcome of statistics instruction, this is one important insight our students invariably get. At this point in the course, there is also coverage of the logic of hypothesis testing.

A considerable amount of class time is spent on the chi-square test. For students to understand how and why expected frequencies are calculated, they must be introduced to the concepts of conditional and joint probability. However, instead of just presenting students with the chi-square statistic, they can be led Socratically to arrive at it themselves by considering the problem of quantifying aggregate discrepancies between expected and observed frequencies. Enabling students to arrive at established statistical formulations themselves is an empowering experience, giving them a sense of ownership over the concept.

This guided self-discovery seems to be one version of the kind of collective problem solving expressly called for by the literature that Garfield (1995) cites and is something that can be done with other statistics, with basic concepts, and with statistical principles. For example, variance becomes a more easily understood measure when students discover for themselves why the numerator needs to be squared. Similarly, the $t$ statistic becomes more com- prehensible when students are encouraged to arrive themselves at a way of measuring how far in standard deviation units an observed value differs from the average value expected by chance.

Knowing how to read a contingency table and which way to calculate percentages is not something students easily learn. One of the factors influencing how well students learn is repetition (Garfield, 1995), and we find that the proper way to read a contingency table is something that must be gone over again and again. For homework, students are asked to run chi-square tests themselves and be prepared to interpret them in class. For some groups of students, 1 or 2 days at this activity is insufficient.

Another key principle of the course design that coincides with Garfield's (1995) recommendations is that the course is student-driven rather than syllabus-driven. That is, the prime objective of the course is to get students comfortable with computer-assisted data analysis in general, not to cover a prespecified number of statistical techniques. If students are basically comfortable with the fundamentals of statistical data analysis, they can always build on their repertoire of basic techniques at a later date if needed. This is particularly true should the students later work on a faculty research project or take postgraduation jobs in which they are expected to participate in data analysis.

The goal is to provide students with a solid base from which to grow in their utilization and application of statistical techniques and principles. Sufficient understanding is not sacrificed in the interests of teaching a fixed agenda of tests. Thus, if the majority of our students learn how to read contingency tables, it is not considered a calamity if the first term proceeds no farther than having completed a full consideration of chi-square, including such issues as problems with low cell counts. If the students master no more than that, they have at least established a degree of comfort with data that will serve them well in the second-term course, on a job, or in graduate school.

At the end of the first term or the beginning of the second, students are introduced to the $t$ test. Considerable time is devoted to this statistical technique, covering theory, computer commands, and interpretation of output. At this time, students are also introduced to random sampling and the central limit theorem. Here, as Garfield's (1995) review suggests, the computer is especially useful for helping students visualize abstract concepts.

One such abstract concept that seems particularly difficult for many students to understand is that of a sampling distribution. Garfield (1995) suggests using the computer to construct various populations and observing the distribution of statistics of samples drawn from them. As it happens, that is the type of exercise we independently developed ourselves. For example, SPSS has a function that draws random subsamples from a data set of any specified size. One exercise required of the students is to draw subsamples from their data: 30 sets of Size 5, 30 sets of Size 10 , and 30 sets of Size 15. Then, by hand, students 
create three separate plots of the distributions of sample means, one plot for each sample size. Finally, they are required to turn in a brief report aimed at demonstrating how the three plots illustrate the operation of the central limit theorem, both the narrowing of the distribution and its increasing normality with increasing sample size. This exercise is an easy, graphic way for the students to visualize the meaning of a sampling distribution, thereby demonstrating an abstract concept in a concrete manner.

In coverage of statistical techniques, the second term typically progresses up to and includes one and two-way analysis of variance. Then, depending on the amount of material mastered by the class, zero-order regression is covered. In this second term, much time is spent on causal thinking (i.e., on the formulation of hypotheses and the construction of causal models). During this part of the second term, students are required to formulate their own causal models, using up to five variables from the data set. These causal models are reviewed by the instructors, with a great deal of attention given to the plausibility of the hypothesized causal mechanisms. Thus, the distinction between causation and covariation is reintroduced, but now in a different context and in a different way than previously presented. This reintroduction of a fundamental concept is in accord with Garfield's (1995) review of the literature, which seems to emphasize the importance of repetition and of developing student understanding of the difference between causation and covariation. We have found this reintroduction quite valuable in reinforcing and solidifying student understanding of the distinction.

The second-term course also includes instruction on how to write up quantitative results. Students' initial tendency is to write their results in such a way that each empirical result stands alone, unintegrated in any coherent way with any of the others. Through feedback on rough drafts, students are taught to integrate their results so as to present a coherent argument. Their concluding homework assignment is a final report on how their hypothesized causal model fared empirically, thereby integrating several threads of the course into a single written product.

\section{SPECIAL FEATURES}

The previous section describes the general features of our overall model for the two-term data analysis and statistics sequence. This is a pedagogical model in which statistics, the analysis of real data, and computer technology are all integrated. The present section explores certain features of the courses in more depth. It also addresses the rationale for some of the less obvious choices made in structuring the courses.

\section{Choice of Mainframe Versus \\ Microcomputer-Based Software}

In the years since creation of the first data analysis course in the early 1980 s, the courses have consistently relied on mainframe statistical packages rather than microcomputer-based statistics packages. This use of mainframe statistical packages has continued despite the fact that Drexel, in 1984, became the first university in the nation to require universal student access to a microcomputer. We were aware of the arguments in favor of the use of mainframe packages for teaching statistics (e.g., Thisted, 1979) and of those advanced for the use of microcomputer-based teaching tools (e.g., Castellan, 1980; Levy, 1983). Similarly, we looked quite closely at the type of considerations for integrating statistics software into instruction discussed by Butler (1986). We also followed the increasing maturity both of microcomputerbased statistical packages (e.g., Butler \& Neudecker, 1989; Lehman, 1986) and of microcomputer-based instructional computing laboratories (e.g., Conn, Stafiniak, DiPasquale, \& Harper, 1988; Hirtle \& Kallman, 1985; Hornby \& Anderson, 1988; Leith, Hamm, Duncanson, \& Senical, 1988; Schneider, 1988).

Ultimately, however, the final decision to continue to utilize a mainframe statistical package, such as SAS or SPSS, was dictated by the environment in which our students work. As a cooperative education institution, Drexel University sends its undergraduates into a wide variety of 6-month cooperative education placements during their 5-year programs. Until relatively recently, the employers of our students tended to rely heavily or exclusively on mainstream statistical packages, such as SAS and SPSS, running on mainframes. Thus, it seemed desirable to instruct students in the use of the type of software and hardware that they would subsequently encounter in their cooperative education experiences. Now, however, use of microcomputers has become sufficiently widespread that we have recently made the transition to student versions of SPSS for personal computers. In addition, we are looking closely at the possibilities opened up by increased access to the Internet and the World-Wide Web (e.g., Briggs \& Sheu, 1998).

\section{Real Versus Artificial Data Sets}

The courses typically utilize a real data set based on someone's research, data that a local community organization needs to have analyzed, or data that the students themselves collect. One disadvantage of using a real data set is that when the students go looking for relationships, they might actually find nothing at all. This prospect is, however, a realistic one. On the other hand, an advantage of a real data set is that it gives students the opportunity to solve problems from which they can learn to evaluate which analytic technique is appropriate for the data and the questions being asked. Thus, students can be challenged to develop their understanding of when to choose a less powerful nonparametric test over a parametric test. Given the appropriate data, students can be confronted with the need to understand the difference between conducting a one-tailed $t$ test and a two-tailed $t$ test.

There is an important consideration in favor of data sets that, time permitting, the students create themselves. The more ownership students have over the data set they eventually analyze, the more engaged they are and the 
more able they are to envision rival causal processes and form interesting hypotheses. When students are presented with someone else's data, one element of such ownership is absent. Accordingly, students are much less in command of the conceptual framework behind the data collection and, therefore, less able to reason effectively about data characteristics and hypotheses. Consequently, it is essential in this case to include coverage of the study, hypotheses, and other considerations that motivated the data collection.

Similarly, regardless of whether the primary data set that the class employs is their own or someone else's, it is important for the students to have some opportunity to work with data that they themselves have entered into the computer. Working only with preentered data sets, students may learn statistics and data analysis yet still be mystified by how the data are entered into the computer. When students code and enter a data set themselves, they gain further ownership over what they are analyzing, while the process of data entry is demystified.

Utilizing a research-grade statistics package (e.g., SAS, SPSS) provides a context in which the teaching of the procedures for working with the data integrates review and discussion of a statistical procedure and its range of application. For example, one of the authors once made available to students in the class a data set created from an American Chemical Society job-satisfaction survey. This data set contained over 50,000 respondents. Student examination of correlations between variables in this data set reinforced quite dramatically and compellingly that the significance of a correlation can be influenced by the number of observations. Similarly, the results helped illustrate that a statistically significant result does not necessarily have any practical significance.

Working with large-scale, nonexperimental data sets helps students to recognize that statistical analysis can be applicable to nonexperimental work. This can be particularly beneficial for some of the psychology majors whose topical content courses (e.g., cognitive psychology, physiological psychology, etc.) tend to include a strong focus on experimental findings and methodologies. The students learn that it is sometimes necessary to transform the raw data in some way to prepare them for analysis, as well as the fact that it is sometimes necessary to "clean" the raw data. They also learn the difficulties created by missing data, as well as how to deal with those problems.

\section{Service Learning Versus Classroom Learning}

A commitment to using real data sets creates the potential for a data analysis course to incorporate a service learning component. Service learning is a form of pedagogy with growing appeal on college campuses. It is an experiential form of education in which students learn by applying what they are learning in class to serving the community. Most applications of service learning are qualitative in nature. Education students, for example, may mentor local school children. Sociology students, similarly, may serve at homeless shelters and apply ethno- graphic techniques of observation. Psychology students interested in child development may likewise serve at child care units.

It is often more difficult to find a way to incorporate service learning into quantitative or technical courses. Service learning, however, does not necessarily require our students to go to the community. For example, the data set used in class can be supplied by local community organizations that need to have data analyzed. Representatives from the community organizations are usually more than happy to come to class, to bring their questionnaires, and to explain to the students what the organization wants to know from the data. In this way, the students get a real sense that their data analysis matters and that it has a genuine real-world application. They see themselves as not only learning but also serving the community in a technical capacity.

Our own courses have often incorporated a service learning component in this way. In the past, for example, our students have analyzed data for the Red Cross and for the United Way, both of which were grateful for the reports generated. The level of engagement with the data that a service component can produce in the students is sometimes startling. In one case, because the students were so committed to helping a community organization, they actually tracked down a fellow student who had dropped the course. After obtaining her share of questionnaires, which would otherwise have been lost, the other students divided up the questionnaires and did the extra data entry themselves. Thus, a data analysis course can turn out to be an ideal candidate for inclusion of a service learning component.

\section{Group Collaboration Versus \\ Individual Homework Assignments}

Two factors that Garfield's (1995) review identifies as being of help to statistics students are frequent feedback and small group activities. The course model being described here integrates these two factors. Although Drexel University is known as a technological university, our psychology and sociology majors still often tend to be intimidated by the computer and anything technical. To reduce the level of intimidation, students are encouraged to work on their homework in pairs or small groups. The expectation is that, in this way, the students can be mutually supportive of each other as they face intimidating tasks. However, students are not required to work in pairs. If students find that their partners are not pulling their own weight, they have the option to dissolve the partnership and work alone. This latter option eliminates one of the complaints often attendant on required teamwork. For the majority of students, however, the partnerships work well.

All homework assignments are graded on a pass-fail basis, and the students are required to repeat a failed assignment until it is graded "pass." These frequent homework assignments are generally related to steps in the pro- 
cess of data analysis that are then expanded to instill a pedagogical point. For example, one homework assignment requires students to enter and prepare their data, which is accomplished more quickly and accurately (and less tediously) when done in pairs. Students then check and clean data by running frequencies and searching for values beyond the acceptable range. Another closely related homework assignment is to construct histograms from the frequency distributions they are asked to generate. At this time, students also learn about different kinds of distribution: normal, uniform, bimodal, and so forth. For homework, students have to sketch and identify the different kinds of distributions they observe.

Students do a number of homework assignments in connection with learning about chi-square. One assignment requires them to generate the observed and expected frequencies for a contingency table and then to duplicate the expected frequencies by hand calculation. After learning about minimal requirements for expected cell frequencies, students are then given homework that requires them to determine whether or not they need to collapse their tables. If the topic has not been previously covered, this assignment is also accompanied by a lesson on recoding data.

When learning the $t$ test, students receive a homework assignment that requires them to obtain two statistically significant results. This assignment requires both that the students run and interpret a $t$ test properly and that they think about the variables in a causal way. In other words, the students must think conceptually about which variables might affect each other, thus increasing the likelihood of a statistically significant result.

Some homework assignments have other pedagogical purposes, such as the assignment related to the central limit theorem, described earlier, in which students generate multiple samples of different sizes and then calculate means and plot the distributions of those means. Another example is an early programming homework assignment with deliberately introduced errors. Finding and debugging these errors helps the students learn to interpret the meaning of error messages.

\section{Quizzes Versus Examinations}

Another key element of the course is frequent quizzes that do not individually carry much weight toward the final grade. Cumulatively, however, the quizzes represent a substantial portion of the course grade. One point of the quizzes is to make the students transfer what they have learned from their notebooks into their heads. Students often take very good notes but seem less likely to read over their notes frequently unless compelled to do so. Thus, a traditional examination-based course can lead to a class of good notebooks instead of a class of good statistical analysts.

Since it is virtually impossible to monitor all students to ascertain whether they have done any programming or other computer-based homework themselves, the quizzes are structured in such a way that only those who have put in time on the homework will understand the quiz materials and do well. Some quizzes require simple calculations, such as computation of an expected frequency for a cell of a contingency table. Other quizzes involve the reading of output and some simple calculations relating the various listed measures. For example, the SPSS output for a $t$ test lists not only individual group means but also the sampling error associated with each. From this information, students are required to create two confidence intervals, one for each sample mean, and to determine whether the two intervals overlap.

For the most part, however, the quizzes do not require any calculations. Instead, they consist of short answer responses to conceptual questions. Students might be asked to explain the conceptual meaning of variance or the $t$ statistic, to explain the meaning of statistical dependence or covariation, to list the criteria of causality, or to explain why covariation does not imply causality. Such questions match the kind of conceptual outcomes that, from the literature, Garfield (1995) suggests are both reasonable and desirable.

After each quiz there is feedback and a chance for the student to attempt the work again. In lieu of a final, students are given the opportunity to redo or retake alternate make-up quizzes that test the same material as those on which the student has not done well. The philosophy here is to give the students the opportunity to learn the material. It is preferable that the students do so at the time it is first presented; but if they succeed in learning the material by the end of the course, that serves the overall objectives almost as well. Our goal is to produce students who are comfortable with computer-assisted data analysis, who understand the basic concepts of statistics, and who, with supervision, can recall and build on what they have learned when applying it at a later date.

\section{CONCLUDING REMARKS}

The first version of the course model presented here was developed in the early 1980 s. Since then, it has been refined and elaborated and has represented a successful method of coping with the curriculum integration problem forecast by Castellan (1986). The two-term computerassisted data analysis sequence is also tightly integrated into the department curriculum. It supports, parallels, and is reinforced by a two-term sequence in research methods, which is often taught by the same instructors. In addition, psychology majors are required to complete a course in experimental psychology. This integration and coupling of courses affords students who follow the recommended sequence in their sophomore year the marketable skills required for the more desirable cooperative education placements. It also enables students to engage in reasonable undergraduate research projects later in 
their education. Some students also elect to go on and do some form of quantitative analysis for their senior thesis, often as part of a faculty member's research.

\section{Reasons for Judging the Course to be a Success}

As noted earlier, course outcomes and the structure of the two-term sequence have not been subjected to any formal summative testing; thus, our confidence in the success of the course is partially experiential and anecdotal. However, the close match between the course structure and the recommendations that Garfield (1995) and Becker (1996) derive from their reviews of the literature on teaching of statistics is highly suggestive. Effectively, the data analysis course sequence seems to be a case study example that embodies many of those recommendations. Thus, many of our choices seem to be supported by the prior results of others, and our experiences are consistent with the reviews and analyses conducted by Becker and by Garfield, thereby lending support for their conclusions.

Our confidence in the success of this course model is also derived from observations of our students after they leave the course. Most students no longer fear computers, computer analysis, or even statistics. Some students actually choose to do more computer-assisted data analysis, even when not required to do so. We find students doing such analyses on their own initiative for projects in other courses. We find that students who elect to do the senior thesis option now willingly choose projects that entail computer-assisted data analysis.

There are still other indirect indicators of success. Some of our students have gone on to jobs that require statistical analysis. In one case, a student-who was not one of our best statistics students-became the statistics guru at his office. Students who choose to go on to graduate school report back that when it comes to their statistics classes, they feel they are well ahead of other students in their degree programs. In one case, admittedly involving one of our very best students, the student went on to a top graduate school in psychology. There, because of her background in data analysis and her experience as a TA for our data analysis courses, she was immediately made the lab instructor for her graduate-level statistics class. In addition, some of our students have conducted projects presented at professional meetings (e.g., Gretto \& Porpora, 1994; Mizuno, Kutzik, \& Porpora, 1995a, 1995b; O’Leary \& Porpora, 1996).

\section{Future Research Issues}

It is a task for future research to demonstrate experimentally whether the full range of pedagogical recommendations deriving from the literature reviews cited here (e.g., Becker, 1996; Garfield, 1995) is demonstrably superior to standard methods. Before that can be done, however, the alternative pedagogical model based on those recommendations must be articulated, developed, and put into practice. The case study example described here represents a step in that direction. In addition, our case example suggests that the outcome measures pro- posed by Garfield need to be supplemented in order to capture what the course model described in this paper is trying to achieve. Outcome measures in future controlled studies should also include a measure of general comfort with more rigorous statistical reasoning and data analysis, as well as a test of dispositional and intellectual readiness to work at a higher level of data analysis.

In summary, the pedagogical model and assumptions that guided the development of the courses described here were developed without direct knowledge of the research results on teaching of statistics reported in recent reviews of the literature (e.g., Becker, 1996; Garfield, 1995). The courses were, however, developed in response to the same dissatisfactions with the traditional textbook and lecture course model. Given the close match between our course implementation and the recommendations derived from those reviews, we feel that our courses represent an instantiation in practice of many of those recommendations. Consequently, and after more than a decade of experience with the course model described here, we are confident enough in the teaching results we have obtained to be able to recommend that faculty who teach statistics can adopt the recommendations of Garfield (1995) and of Becker (1996) with the expectation that some of the techniques do seem to help improve statistics education.

\section{REFERENCES}

BECKER, B. J. (1996). A look at the literature (and other resources) on teaching statistics. Journal of Educational \& Behavioral Statistics, 21, 71-91.

BrigGS, N. E., \& SHEU, C.-F. (1998). Using Java in introductory statistics. Behavior Research Methods, Instruments, \& Computers, 30, 246-249.

BUTLER, D. [L.] (1986). Integrating statistical software into laboratories and laboratory courses. Behavior Research Methods, Instruments, \& Computers, 18, 241-244.

Butler, D. L., \& Neudecker, W. (1989). A comparison of inexpensive statistical packages for microcomputers running MS-DOS. Behavior Research Methods, Instruments, \& Computers, 21, 113-120.

CASTELlan, N. J., JR. (1980). The use of matrix manipulation programs in teaching statistical methods. Behavior Research Methods, Instruments, \& Computers, 12, 172-177.

Castellan, N. J., JR. (1986). Issues in the effective use of computers in introductory and advanced courses in psychology. Behavior Research Methods, Instruments, \& Computers, 18, 251-256.

Conn, G., Stafiniak, P., DiPasquale, M., \& Harper, L. (1988). Effects of teaching an introductory psychology laboratory using a computerized research tool. Behavior Research Methods, Instruments, \& Computers, 20, 184-187.

GARFIELD, J. (1995). How students learn statistics. International Statistical Review, 63, 25-34.

GARFIELD, J., \& AHLGREN, A. (1988). Difficulties in learning basic concepts in statistics: Implications for research. Journal for Research in Mathematics Education, 19, 44-63.

Gretto, T., \& Porpora, D. V. (1994, March). Learning styles and philosophical reflectiveness. Paper presented at the meeting of the Eastern Sociological Society, Baltimore.

Hirtle, S. C., \& Kallman, H. J. (1985). An integrated approach to computer usage in the teaching of experimental psychology. Behavior Research Methods, Instruments, \& Computers, 17, 359-362.

HoRNBY, P., \& ANDERSON, M. (1988). Using computers in teaching introductory psychology. Behavior Research Methods, Instruments, \& Computers, 20, 180-183.

LeHMAN, R. S. (1986). Macintosh statistical packages. Behavior Research Methods, Instruments, \& Computers, 18, 177-187. 
Leith, C. R., Hamm, H. D., Duncanson, C., \& Senical, T. (1988). A computer-driven undergraduate laboratory and related support logistics. Behavior Research Methods, Instruments, \& Computers, 20, 188-190.

LEVY, C. M. (1983). Microcomputer-based tutorials for teaching statistics. Behavior Research Methods, Instruments, \& Computers, 15 , 127-139.

MEVARECH, Z. (1983). A deep structure model of students' statistical misconceptions. Educational Studies in Mathematics, 14, 415-429.

Mizuno, M., Kutzik, D., \& PorPoRA, D. V. (1995a, March). African American community dwelling elderly: Formal and informal supports, service access, and health needs. Paper presented at the meeting of the Eastern Sociological Society, Philadelphia.

Mizuno, M., KutziK, D., \& Porpora, D. V. (1995b, November). African American community dwelling elderly: The results of a participatory research project. Paper presented at the meeting of the Gerontological Society of America, Los Angeles.

O'Leary, L. K., \& Porpora, D. V. (1996, March). Athletic competitiveness and gender. Paper presented at the meeting of the Eastern Sociological Society, Boston.
SCHNEIDER, W. (1988). Micro Experimental Laboratory: An integrated system for IBM PC compatibles. Behavior Research Methods, Instruments, \& Computers, 20, 206-217.

Scholz, R. (1991). Psychological research in probabilistic understanding. In R. Kapadia \& M. Borovcnik (Eds.), Chance encounters: Probability in education (pp. 213-254). Dordrecht: Kluwer.

ShaUGHNESSY, J. M. (1977). Misconceptions of probability: An experiment with a small-group activity-based model building approach to introductory probability at the college level. Education Studies in Mathematics, 8, 285-316.

THISTED, R. A. (1979). Teaching statistical computing using computer packages. American Statistician, 33, 27-35.

VON GLASERSFELD, E. (1987). Learning as a constructive activity. In C. Janvier (Ed.), Problems of representation in the teaching and learning of mathematics (pp. 3-17). Hillsdale, NJ: Erlbaum.

(Manuscript received October 14, 1998; revision accepted for publication March 15, 1999.) 